ISSN: 2637-4692

\title{
Applied Lasers in Pediatric Dentistry
}

\author{
Mohammad Karimi* \\ Sepideh Dental Clinic, Department of Pediatric Dentistry, Iran \\ *Corresponding author: Mohammad Karimi D.M.D, Sepideh Dental Clinic, Department of pediatric Dentistry, Iran
}

\section{Introduction}

Fear and anxiety of dentistry are very common in children and adolescents. Although these unpleasant feelings are due to several factors, one of its main causes is hearing the painful experiences of dental work from a friend or family members.

For pediatric dentists, uncontrolled panic in young patients can lead to physical reactions such as screaming, crying or psychological reactions such as fear and lack of cooperation with the dentist. Subsequently, this will cause the problem in control of the child's behavioral, a contention between the parents and the treatment staffs, the failure to achieve the desired treatment, and eventually dissatisfaction of the parents.

What is the solution to this problem? What can change all these unpleasant things in a positive direction? Clinical experience has shown that dental treatment of children with lasers has many advantages over conventional methods. Painless dentistry reduces the time of restorative treatments; eliminates the need for highspeed turbines which might create shaking or vibration [1], smell, and fear; reduces or eliminates the need for local anesthesia, sutures, and administration of analgesics or antibiotics.

\section{Lasers in Pediatric Dentistry}

With the least need for anesthetics and the removal of terrifying dental instruments such as high-speed turbines and lowspeed hand pieces, reducing the bleeding, stress, fear, and pain, this technology allows the treatment to be more ideal; and the toddlers will feel more comfortable and happier during the dental procedures. On the other hand, this makes a friendly relationship between the dentist and the child.

In addition to restorative treatments, the laser has other uses in pediatric dentistry, including the replacement of methods such as frenectomy and pulpotomy etc. Lasers such as Argon, Diode, YAG$\mathrm{Nd}, \mathrm{YAG}-\mathrm{Er}, \mathrm{YSGG}-\mathrm{Cr}-\mathrm{Er}$, and $\mathrm{CO}_{2}$ [2] not only can reduce stress but also provide fearless dental treatments. Lasers are more accurate than electro surgery devices and cause less necrosis in adjacent tissues.

\section{Application in Decayed Teeth Restoration}

Lasers are very effective on the teeth decay in children. They help with more accurate and quick detection of caries areas and, due to their high sensitivity and precision, ultimately, preserve a lot of teeth structures. They also prepare the structure around the tooth to get the restorative materials and will minimize the destruction of healthy areas. In addition, it improves the enamel and dentin conditions for binding to the restorative materials. Many types of lasers are used in pediatric dentistry. Laser devices such as Diagnodent are used to detect caries [3]. This device measures the amount of fluorescence light which passes through the occlusal surface of the tooth and, in a ratio with mineralization, converts it to a small extent to determine the relative rate of tooth decay[4]. Argon lasers are available to tighten composite restorations and soft tissue surgery.

\section{Application in Soft Tissue Surgery}

$\mathrm{Co}_{2}$ lasers will be used for surgical treatment of soft tissue lesions, especially when controlling bleeding, evaporation, and accurate tissue cutting $[5,6]$. However, due to the possibility of child mobility and lack of cooperation, it may not be a good laser for working with children.

Devices such as Nd-YAG lasers at $1064 \mathrm{~nm}$ wavelengths, as well as continuous or alternating Diode lasers, are not effective for the hard tissue, but are used to cut soft tissue. These types of lasers are suitable for treating soft tissue pigmented lesions because they are absorbed in hemoglobin and control bleeding [7-9].

With the introduction and development of Erbium family lasers, pediatric dentists have found a safe and effective laser in the 
treatment of soft and hard lesions of the oral cavity. The depth of the diffusion of Erbium lasers in the tissue is low; its absorption is high in water; does not have thermal damage, and its reflective properties are so low that it is desirable to work with children [9].

Lasers which are used on hard tissue, their tips do not touch the tissue and will use water spray. In soft tissue surgery, the use of water sprays is optional, and surgeries are performed by the contact of the tips of the hand piece on the tissue $[8,9]$.

For example, the treatment of aphthous ulcers and herpes simplex lesions occurs when the tip of the device is far from the lesion. The benefits of treating patients with Erbium family lasers include the bactericidal effect that can cause sterilization of the workplace, and the analgesic effect on the target tissue that is similar to the Nd-YAG device.

\section{Safe Replacement for Frenectomy}

The long frenum is a complication that limits the movement of the tongue and the lips. Problems with the baby's nutrition and difficulties that arise in his speech in the future are the main complications of this abnormality that can be treated by a method of frenectomy. This method, despite its simplicity, requires general anesthesia. Nowadays, with the help of a laser, it is possible to minimize the adverse effects [10] without having to undergo the conventional (traditional) frenectomy, suturing or even referral to the hospital. In the laser procedure, the child can start normal nutrition after the procedure, and the convalescence will take faster [10], while with a conventional frenectomy, the recovery is 3 weeks.

\section{Laser or Pulpotomy}

Pulpotomy is a method used to save an infected tooth. The use of this method is not recommended for children with chronic illness and immune system problems [9]. Due to these limitations, the application of the laser method is more practical. It is believed that the laser is much less dangerous and safer.

Although increased demand for painless dentistry has led to more use of lasers, these methods are still not as popular in pediatric dentistry. Perhaps the general impression is that the cost of lasers is high, but with little consideration, today, lasers are more efficient, less troublesome than ever, and they can eliminate the irreparable costs of old methods.

\section{Conclusion}

Since the pediatric behavioral control in dentistry is one of the major goals of the dentist, the preventive treatment of other treatments on oral and dental care in an environment without stress and fear is of importance. Lasers in pediatric dentistry are the topics which are very important. The dentist is obliged to record all the laser treatment procedures, including the amount of energy, number of pulses, and power and radiation time in the patient's case. The laser allows the dentist to perform more conservative methods on soft and hard tissues with minimal discomfort and pain without any needs for injection or application of anesthesia with minimal bleeding. By omitting the anesthetic injection and turbine vibrations and the bad smell of ordinary tooth preparation, the satisfactory of the child and parents is provided. The use of lasers has changed in the form of dental treatments and may be used as conventional dental devices in the future, like ordinary hand pieces.

\section{References}

1. Evans D, Reid J, Strang R, Stirrups DA (1999) comparison of laser with other methods of assessing the vitality of traumatized anterior teeth. Endod Dent Traumatol 15: 284-290.

2. Mason C, Hopper C (1994) The use of $\mathrm{CO}_{2}$ laser in the treatment of gingival fibromatosis: A case report Int J Paediatr Dent 4: 105-109.

3. Attrill DC, Ashley PF (2001) Occlusal caries detection in primary teeth: a comparison of DIAGNO dent with conventional methods. Br Dent J 190(8): 440-443.

4. Sanchez Figueras A Laser Fluorescence Detection of Occlusal Caries Clinical utilization of the KaVo DIAGNOdent.

5. Melcer J (1998) The use of the $\mathrm{CO}_{2}$ laser beam in Dentistry Proc $6^{\text {th }}$ Int Congr on Laser in Dentistry Maui Hawaii, pp. 28-30.

6. Vitale MC, Tardieu C (1999) Clinical use of $\mathrm{CO}_{2}$ laser in Pediatric Oral Surgery Proc $17^{\text {th }}$ Congr of the Intern Association of Paed Dent 1-9 September1999 London. Int Jour Paed Dent 9(suppl1): 22.

7. Moritz A, Schoop U, Goharkhay K, Sperr W (1998) Advantages of a pulsed $\mathrm{CO}_{2}$ laser in direct pulp capping: A long-term in vivo study Lasers Surg Med 22: 288-293.

8. Doneria Divya, Thakur Seema, Singhal Parul, Chauhan Deepak, Jayam Cheranjeevi et al. (2015) Erbium Lasers in Paediatric Dentistry.

9. Neena E, Parameswarappa Poornima, Edagunji Ganesh, Korishettar Roopa, Bharath P et al. (2015) Lasers in pediatric dentistry: A review Int J Contemp Dent Med Rev 10.15713/ins.ijcdmr.29.

10. Kumar G, Rehman F, Chaturvedy V (2017) Soft Tissue Applications of Er Cr: YSGG Laser in Pediatric Dentistry. Int J Clin Pediatr Dent 10(2): 188-192. 
(C) (P) This work is licensed under Creative Commons Attribution 4.0 License

Submit Article

DOI: 10.32474/MADOHC.2019.03.000168

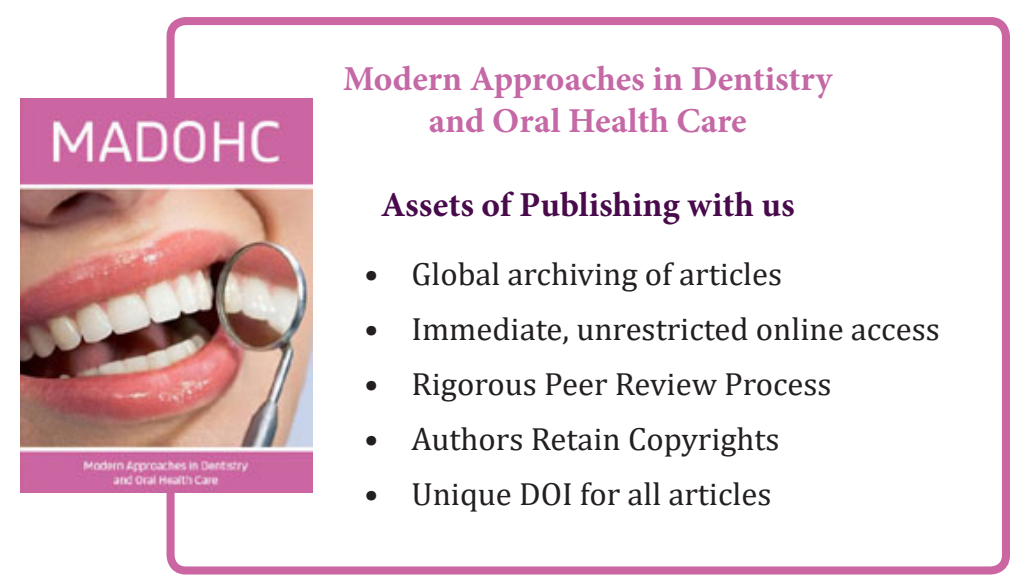

